\title{
Introduction to Knowledge Society, Culture, and Knowledge Systems Minitrack
}

\author{
Minna Rollins \\ University of West Georgia \\ mrollins@westga.edu
}

\author{
Mika Gabrielsson \\ University of Eastern Finland \\ mika.gabrielsson@uef.fi
}

\author{
Nilmini Wickramasinghe \\ Deakin University \\ n.wickramasinghe@deakin.edu.au
}

Our minitrack focuses on various cultural aspects of Knowledge Management and Knowledge Systems. Both papers in this minitrack have a context of International New $\mathrm{V}$ entures (INV), the companies that internationalize quickly after inception. INVs are fruitful organizations to study knowledge management and information systems because these companies and their networks share and use knowledge across cultures and country borders. The research considering IS and knowledge management in INVs is still its infancy.

The first paper of this minitrack, by Fraccastoro and Gabrielsson, explores the impact of social media usage on the internationalization process of International New Ventures (INVs). Authors used a longitudinal single case study approach. The case company, Beta CRM, is based in Italy and it has had a worldwide presence serving 100 countries from the first year of business. Beta CRM commercializes CRM software enabling sales force automation by simplifying the management of sales networks and sales activities. The key findings show that during the company's introductory phase, social media had a primary role in heightening the speed of internationalization. Later, in more mature phases, the need for direct sales personnel and personal relationships increased.

The second paper in this minitrack by Pehrsson and Rollins, explores the relationship between market knowledge and dynamic capabilities in a local unit of an INV. The authors build a conceptual model that illustrates the impact of broad and deep market knowledge on the local unit's competitive advantage and performance. It is proposed that the INV unit needs dynamic capabilities in order to efficiently convert market knowledge into competitive advantage and then performance.

We want to thank all authors and reviewers this year. 